\title{
Análise quantílica dos fatores de influência na arrecadação do Regime Geral de Previdência Social em Minas Gerais
}

\section{Analysis of regression quantiles: factors of influence in the social security collection in Minas Gerais, brazil}

\author{
Aline Gomes Peixoto Gouveia \\ Professora no Departamento de Ciências Contábeis da Universidade Federal de Juiz de Fora (UFJF \\ - GV). Mestre em Administração Pública - Universidade Federal de Viçosa (UFV) \\ E-mail: aline.gouveia@ufv.br
}

\section{Tarrara Alves Horsth}

Professora no Departamento de Ciências Contábeis da Universidade Federal de Juiz de Fora (UFJF - GV). Mestre em Administração Pública - Universidade Federal de Viçosa (UFV)

E-mail: tarraraas@gmail.com

\section{Walmer Faroni}

Professor Titular do Departamento de Administração e Contabilidade da Universidade Federal de Viçosa (UFV). Doutor em Administração e Finanças Públicas pela Universidade de Valencia E-mail: walmerfaroni@gmail.com

Resumo: O Regime Geral de Previdência Social (RGPS) possui modelo de financiamento de repartição simples, sendo necessário conhecer o montante de contribuições capaz de conservar o fluxo de pagamento dos benefícios em determinado período. Este artigo teve como objetivo identificar os fatores que influenciam os diferentes níveis de arrecadação previdenciária do RGPS nos municípios de Minas Gerais, por meio da técnica de Regressão Quantílica, considerando os a base de dados do ano de 2010. A revisão literária buscou variáveis que pudessem influenciar a arrecadação e consequentemente interferir na sustentabilidade do regime. Em sequência, compararam-se os resultados obtidos na análise multivariada com o que preconiza a literatura, constatou-se que, nestes municípios, a arrecadação está relacionada a aspectos socioeconômicos, financeiros e demográficos representados neste trabalho pela taxa de fecundidade, rendimento, taxa de desemprego, trabalho informal e pelo PIB per capita. Esses fatores influenciam na arrecadação e na sustentabilidade do sistema previdenciário a médio e longo prazo; bem como na garantia de pagamento dos benefícios aos segurados. Estes benefícios são responsáveis pela distribuição de renda entre a população, pela melhoria da qualidade de vida, garantia de proteção social e fortalecimento da economia dos pequenos municípios, entre outros aspectos que ratificam a Previdência Social como umas das principais políticas públicas do país.

Palavras chave: arrecadação previdenciária; regime geral de previdência social; políticas públicas; sustentabilidade do sistema previdenciário; regressão quantílica. 
GOUVEIA, Aline G. P.; HORSTH, Tarrara A.; FARONI, Walmer. Análise quantílica dos fatores de influência na arrecadação do Regime Geral de Previdência Social em Minas Gerais

\begin{abstract}
The Social Security has a simple model for distribution financing, so this is necessary to know the amount of contributions capable of maintaining the flow of payment of benefits in a given period. This paper aimed to identify the factors that influence the different levels social security collection in the cities of Minas Gerais, in 2010, through the Quantile Regression. The literature review looked for variables that could influence the social security collection. These were compared with the results obtained in the multivariate analysis, it was verified that, in the cities of study, the social security collection is related to the socioeconomic, financial and demographic aspects, represented in this study by the rate of fertility, income, unemployment rate, informal work and GDP per capita. These factors influence the social security collection and sustainability of this system in the medium and long deadline, as in the guarantee of payment of benefits to the insured. These benefits are responsible for the distribution of income among the population, for improving the quality of life, guaranteeing social protection and strengthening the economy of small cities, among other aspects that ratify Social Security as one of the main public policies of the country.
\end{abstract}

Keywords: social security collection; public policy; sustainability of the social security system; quantile regression.

\title{
1. Introdução
}

A Previdência Social é uma área de políticas públicas que estabelece um padrão de proteção social com o objetivo de contribuir com recursos financeiros à classe trabalhadora. $\mathrm{O}$ sistema previdenciário brasileiro se assemelha ao de países como Japão, Estados Unidos e Alemanha, em que os jovens contribuem para financiar as aposentadorias e pensões da população idosa. O modelo de financiamento do sistema é preocupante nestes e em outros países, e conforme Ellery e Bugarin (2003) possivelmente estará comprometido até 2030.

No Brasil, estimativas e projeções da situação financeira do Regime Geral de Previdência Social (RGPS) para o período de 2003 a 2030, realizadas por Lima (2013), apontam que em 2030 não haverá nenhuma possibilidade de equilíbrio no grupo de benefícios que constituem a cobertura previdenciária do RGPS.

O RGPS, gerido pelo Instituto Nacional do Seguro Social (INSS), possui modelo de financiamento de repartição simples, onde se faz necessário conhecer o montante de contribuições capaz de conservar o fluxo de pagamento dos benefícios em determinado período. Este modelo é vulnerável às alterações na estrutura etária da população, por equacionar os custos e o conjunto de benefícios a serem pagos dentro de um mesmo exercício (Lima, 2013).

Revista Brasileira de Políticas Públicas e Internacionais, v.2, n.2, Dezembro/2017, pp. 135-151. 
GOUVEIA, Aline G. P.; HORSTH, Tarrara A.; FARONI, Walmer. Análise quantílica dos fatores de influência na arrecadação do Regime Geral de Previdência Social em Minas Gerais

Conforme dados do Ministério da Previdência Social [MPS] (2010), a Previdência Social emitiu benefícios no valor de 224,8 bilhões de reais em 2009 (7,15\% do Produto Interno Bruto), para 28,1 milhões de pessoas. O regime geral, especificamente, evidenciou déficit superior a 60 bilhões de reais em 2010 que tende a se agravar com a inversão da pirâmide etária brasileira, exigindo maior esforço das finanças públicas para pagamento de benefícios no longo prazo (Lima, 2013).

Os benefícios concedidos pelo RGPS são de caráter previdenciário, assistencial e acidentário, e interferem diretamente no bem-estar da sociedade, pelo seu caráter protetivo como mecanismo de distribuição de renda e por impactos sobre a pobreza ${ }^{1}$. Fica evidente a importância da Previdência Social no âmbito das políticas sociais brasileiras, entretanto é necessário o equilíbrio financeiro e atuarial.

Deve se considerar, além de aspectos sociais, os fatores econômicos para se ter um sistema previdenciário sustentável e garantidor do bem-estar social. Neste sentido, o Estado tem promovido reformas constitucionais perante as alterações de aspectos sociais, como o aumento da expectativa de vida, a baixa fecundidade, (Ferraro, 2010), e econômicos, como a inflação elevada, taxa de juros e a indexação de diversos benefícios ao salário mínimo (Silva, Costa, \& Dias, 2014).

Neste contexto, considera-se que a Previdência Social brasileira possui caráter contributivo, mas com filiação obrigatória, em conformidade com critérios que resguardem o equilíbrio financeiro e atuarial, e que ao Estado cabe assegurar renda ao cidadão com incapacidade laborativa e a seus dependentes. Ao passo que o custo financeiro dos direitos se tornou destoante em relação aos ingressos que integram as receitas estatais, indaga-se sobre quais fatores podem interferir na sustentabilidade do modelo de financiamento do RGPS brasileiro.

A sustentabilidade, neste artigo, refere-se ao equilíbrio financeiro (equivalência entre receitas e despesas) e ao equilíbrio atuarial para o financiamento da Previdência Social. Embora existam estudos nesta área, têm se trabalhado pouco a relação entre variáveis sociais, demográficas e econômicas com as receitas do RGPS, com o intuito de obter e analisar os fatores pertinentes ao equilíbrio financeiro em prol da manutenção da política pública previdenciária. Desta forma, o

\footnotetext{
${ }^{1}$ Reis, Silveira e Braga (2013), Carvalho (2012), Hoffmann (2010), Silveira (2008), Cavalieri e Pazello (2005) e França (2004).
}

Revista Brasileira de Políticas Públicas e Internacionais, v.2, n.2, Dezembro/2017, pp. 135-151. 
GOUVEIA, Aline G. P.; HORSTH, Tarrara A.; FARONI, Walmer. Análise quantílica dos fatores de influência na arrecadação do Regime Geral de Previdência Social em Minas Gerais

objetivo geral deste estudo consiste em identificar os fatores que influenciam os diferentes níveis de arrecadação previdenciária do RGPS nos municípios do estado de Minas Gerais.

Especificamente este estudo tem por finalidade realizar a revisão literária em busca das variáveis que podem influenciar a arrecadação previdenciária; identificar as variáveis que afetam os diferentes níveis de arrecadação previdenciária em Minas Gerais por meio da Regressão Quantílica; e comparar os resultados obtidos na análise multivariada com o que preconiza a literatura.

\section{Referencial bibliográfico}

\subsection{Sustentabilidade do sistema previdenciário}

A Previdência Social é a política garantidora da renda ao segurado e familiares perante as situações de acidente, gravidez, morte, prisão, doença ou velhice (Instituto Nacional do Seguro Social [INSS], 2009); e pode ser caracterizada, mesmo que restritivamente, como seguro social, por ser fundamentada em contribuições prévias (Oliveira, 1992). É necessário que o sistema previdenciário seja sustentável, mesmo com as significativas modificações econômicas, sociais, demográficas e políticas ocorridas na sociedade, conservando seu equilíbrio atuarial e financeiro (Silva et al., 2014).

O interesse em proporcionar essa sustentabilidade não se restringe ao Brasil, uma vez que a maior parte dos sistemas formais de seguridade social no mundo realiza o pagamento de benefícios com base no tempo de contribuição e na renda, com financiamento proveniente de tributos que incidem sobre a folha de pagamento; e são gerenciadas pelo governo (James, 2001). Além disso, outros países também discutem sobre o ajustamento dos sistemas previdenciários às alterações socioeconômicas e demográficas, visando a garantia da proteção social conforme os parâmetros de sustentabilidade financeira e atuarial (Thompson, 2000).

A sustentabilidade do sistema previdenciário brasileiro tem passado por complicações desde a década de 1960, quando passou o modelo de financiamento de capitalização para o de repartição, se intensificando com a Constituição de 1988 que ampliou as garantias de proteção da seguridade social. Segundo Afonso (2003, p. 24), ao se referir às garantias previstas pela Constituição, a "habilidade em criar novos direitos (e despesas) não foi acompanhada, com análoga competência, na criação de obrigações (e fontes de financiamento) compatíveis”.

Revista Brasileira de Políticas Públicas e Internacionais, v.2, n.2, Dezembro/2017, pp. 135-151. 
GOUVEIA, Aline G. P.; HORSTH, Tarrara A.; FARONI, Walmer. Análise quantílica dos fatores de influência na arrecadação do Regime Geral de Previdência Social em Minas Gerais

Embora o RGPS apresente crescimento das receitas ao longo dos anos, aumentando em mais de 300 bilhões de reais a arrecadação de 2001 a 2012, verifica-se que o saldo remanescente dos dispêndios do regime geral frente aos valores arrecadados é deficitário, chegando a mais de R\$ 42 bilhões de reais em 2010. Os problemas financeiros enfrentados pelo RGPS, decorrentes do modelo de repartição simples, são evidenciados em estudos como o de Lima (2013), Leite, Ness e Kotzle (2010), Cordeiro (2006) e Bertussi e Tejada (2003).

Há a necessidade de se pensar em novas reformas visando resguardar o sistema previdenciário perante possíveis mudanças no cenário econômico e social, considerando que a receita própria da Previdência pode ser comprometida por fatores como o aumento da população idosa e o trabalho informal, a fim de evitar complicações no equilíbrio financeiro atuarial e consequentemente na sustentabilidade do sistema a médio e longo prazo.

\subsection{Fatores influentes na arrecadação do Regime Geral de Previdência Social}

Neste tópico estão alguns estudos sobre resultado previdenciário e os principais fatores que podem influenciar a arrecadação do RGPS, como os fatores demográficos, o PIB, o mercado informal, entre outros.

Entre os fatores demográficos destacam-se as taxas de fecundidade e a idade. De acordo com Santos (2004) a taxa de fecundidade influencia a arrecadação previdenciária por aumentar a quantidade de contribuintes, ao passo que reflete no número de possíveis beneficiários. A disposição por idade também influencia na razão entre contribuintes e beneficiários, assim como no resultado de regimes previdenciários como o RGPS (Santos, 2004; Leite et al., 2010).

Os fatores demográficos são amplamente abordados em pesquisas sobre equilíbrio financeiro ou sustentabilidade, propriamente dita. No trabalho de Lima (2013), a autora realizou estimativas e projeções para o período de 2003 a 2030, e constatou que as expectativas de equilíbrio das contas previdenciárias para 2011 eram de 5\% e no ano de 2030 não foi identificada possibilidade alguma nesse sentido.

O estudo de Leite et al. (2010) também confirma a importância dos fatores demográficos e expõe outras variáveis (rendimentos, salário mínimo, desemprego e trabalho informal nos benefícios) que exercem influência nas receitas e no resultado financeiro do RGPS. Também o

Revista Brasileira de Políticas Públicas e Internacionais, v.2, n.2, Dezembro/2017, pp. 135-151. 
GOUVEIA, Aline G. P.; HORSTH, Tarrara A.; FARONI, Walmer. Análise quantílica dos fatores de influência na arrecadação do Regime Geral de Previdência Social em Minas Gerais

trabalho de Klieber (2004), expõe que o rendimento dos trabalhadores afeta o resultado financeiro, visto que o aumento na renda proporciona crescimento imediato na arrecadação ao passo que os benefícios futuros também tendem a serem maiores.

Entre as variáveis citadas na literatura o salário mínimo, refere-se à remuneração mínima destinada ao trabalhador, compondo a folha de pagamento ao qual incidem as contribuições previdenciárias, influenciando assim a arrecadação. Por outro lado, cerca de dois terços dos benefícios estão indexados ao salário mínimo (Caetano, 2006), visto que o ajuste dos benefícios emitidos, entre outros fatores, é baseado nos salários de contribuição (Ferraro, 2010).

Outro fator é apontado por Miranda (2010): o trabalho informal, aquele exercido pelo trabalhador sem carteira assinada e por aqueles que trabalham por conta própria (Instituto Brasileiro de Geografia e Estatística [IBGE], 2012). Além desse, o desemprego também gera impactos no RGPS, pois contribuições sobre a folha de pagamento são a principal fonte de receita (Ramos, 2007; Leite et al., 2010).

Outro estudo que também utilizou fatores como desemprego, trabalho informal e salário, assim como o Produto Interno Bruto (PIB) e taxa de juros, foi o desempenhado por Silva et al. (2014). Os autores constataram que a taxa de juros e o salário impactam as receitas, e a taxa de desemprego e o salário possuem relação com as despesas, apontando a importância da diversificação das fontes de receita em prol do equilíbrio financeiro.

Taxas de juros altas desestimulam produção e o consumo, e assim, a oferta de emprego. Além disso, com juros altos aumenta o custo da dívida pública, o que implica em desvios de recursos orçamentários que poderiam ser destinados a programas sociais, como a Previdência Social, para o pagamento da dívida (Silva, 2014). Para os estudos de Silva (2014), Leite et al. (2010) e Ferraro (2010) a taxa Selic foi considerada como indicador da taxa de juros, por ser a taxa básica de juros na economia brasileira e por ser adotada pelo INSS para correções de dívidas.

Para Silva (2014) o PIB está relacionado ao resultado previdenciário, pois o crescimento econômico influencia a geração de postos de trabalho, o que aumenta o número de contribuintes e futuramente a quantidade de beneficiários.

No trabalho de Além e Giambiagi (1997) a inflação é posta como motivo de corrosão do valor real dos benefícios, contribuindo com a diminuição da tendência de crescente das despesas do

Revista Brasileira de Políticas Públicas e Internacionais, v.2, n.2, Dezembro/2017, pp. 135-151. 
GOUVEIA, Aline G. P.; HORSTH, Tarrara A.; FARONI, Walmer. Análise quantílica dos fatores de influência na arrecadação do Regime Geral de Previdência Social em Minas Gerais

regime geral. Embora a inflação também aja sobre a arrecadação previdenciária, visto que as receitas do RGPS são baseadas na remuneração dos contribuintes (Leite et al., 2010).

Após a exposição dos fatores de influência, torna-se necessário apresentar a variável previdenciária: as receitas previdenciárias. São apontadas como aquelas constituídas pelas contribuições previstas na legislação, provenientes de trabalhadores, empresas, segurados, outros recebimentos financeiros, outros recebimentos próprios, por antecipações de receita do Tesouro Nacional e transferências da União (Silva, 2014; Leite et al., 2010).

De modo geral, a literatura aponta fatores demográficos, rendimentos, trabalho informal, salário mínimo, taxa de juros, desemprego, PIB e inflação para se tratar do equilíbrio do sistema da Previdência Social; e como variável previdenciária de interesse, as receitas previdenciárias.

\section{Procedimentos metodológicos}

A partir de estudos já realizados, foram selecionadas as seguintes variáveis na tentativa de compor o modelo de regressão que busca identificar os fatores que influenciam a arrecadação previdenciária do RGPS, conforme o Tabela 1:

Tabela 1: Descrição e fonte de coleta das variáveis

\begin{tabular}{|c|c|c|c|}
\hline Variáveis & Definição & $\begin{array}{l}\text { Unidade } \\
\text { de } \\
\text { Medida }\end{array}$ & $\begin{array}{l}\text { Fonte de } \\
\text { coleta das } \\
\text { variáveis }\end{array}$ \\
\hline $\begin{array}{l}\text { Arrecadação } \\
\text { Previdenciária } \\
\text { per capita } \\
\text { (APC) }\end{array}$ & $\begin{array}{l}\text { O valor arrecadado compreende os recolhimentos } \\
\text { provenientes de todas as receitas incluídas na Guia } \\
\text { de Previdência Social (GPS), em razão da população. } \\
\text { Abrangem receitas de contribuições sociais } \\
\text { patrimoniais, devolução de benefícios, reclamatória } \\
\text { trabalhista e outros. Estes dados correspondem à } \\
\text { rubrica } 11 \text { da GPS, que inclui contribuições relativas } \\
\text { a outras entidades e os acréscimos; dividido pelo } \\
\text { número de habitantes de cada município }\end{array}$ & $\begin{array}{l}\text { Em reais } \\
(\mathrm{R} \$)\end{array}$ & MPS $^{1}$ \\
\hline $\begin{array}{l}\text { Taxa de } \\
\text { fecundidade } \\
\text { (TFEC) }\end{array}$ & $\begin{array}{l}\text { Número médio de filhos que uma mulher deverá ter } \\
\text { ao terminar o período reprodutivo ( } 15 \text { a } 49 \text { anos de } \\
\text { idade). }\end{array}$ & $\begin{array}{l}\text { Porcen- } \\
\text { tagem } \\
(\%)\end{array}$ & $\begin{array}{l}\text { Índice } \\
\text { Mineiro de } \\
\text { Responsa- } \\
\text { bilidade }\end{array}$ \\
\hline
\end{tabular}

Revista Brasileira de Políticas Públicas e Internacionais, v.2, n.2, Dezembro/2017, pp. 135-151. 
GOUVEIA, Aline G. P.; HORSTH, Tarrara A.; FARONI, Walmer. Análise quantílica dos fatores de influência na arrecadação do Regime Geral de Previdência Social em Minas Gerais

\begin{tabular}{|c|c|c|c|}
\hline & & & $\begin{array}{l}\text { Social } \\
(\text { IMRS) }\end{array}$ \\
\hline $\begin{array}{l}\text { Razão de } \\
\text { Dependência } \\
\text { Demográfica } \\
\text { dos Idosos } \\
\text { (RDEP) }\end{array}$ & $\begin{array}{l}\text { A idade será representada pela Razão de } \\
\text { dependência. Esta é medida pela razão entre a } \\
\text { porcentagem de pessoas acima de } 60 \text { anos e a } \\
\text { porcentagem de pessoas com idade de } 15 \text { a } 59 \text { anos } \\
\text { (população potencialmente ativa). }\end{array}$ & $\begin{array}{l}\text { Porcen- } \\
\text { tagem } \\
(\%)\end{array}$ & $\begin{array}{l}\text { Instituto } \\
\text { brasileiro } \\
\text { de } \\
\text { Geografia } \\
\text { e } \\
\text { Estatística } \\
(\text { IBGE) }\end{array}$ \\
\hline $\begin{array}{l}\text { Rendimento } \\
\text { (RENOCUP) }\end{array}$ & $\begin{array}{l}\text { Média dos rendimentos de todos os trabalhos das } \\
\text { pessoas ocupadas de } 18 \text { anos ou mais de idade. }\end{array}$ & $\begin{array}{l}\text { Em reais } \\
(\mathrm{R} \$)\end{array}$ & IMRS $^{2}$ \\
\hline $\begin{array}{l}\text { Taxa de } \\
\text { desemprego } \\
\text { (TDES) }\end{array}$ & $\begin{array}{l}\text { Taxa de desocupação da população de } 18 \text { anos ou } \\
\text { mais de idade. }\end{array}$ & $\begin{array}{l}\text { Porcen- } \\
\text { tagem } \\
(\%)\end{array}$ & $\mathrm{IMRS}^{2}$ \\
\hline $\begin{array}{l}\text { Trabalho } \\
\text { informal } \\
\text { (TINF) }\end{array}$ & $\begin{array}{l}\text { A quantidade de empregados sem carteira assinada } \\
\text { mais a quantidade de trabalhadores por conta própria, } \\
\text { dividido pela população ocupada. }\end{array}$ & $\begin{array}{l}\text { Porcen- } \\
\text { tagem } \\
(\%)\end{array}$ & IBGE $^{3}$ \\
\hline $\begin{array}{l}\text { Produto } \\
\text { Interno Bruto } \\
\text { Per Capita } \\
\text { (PIB PC) }\end{array}$ & $\begin{array}{l}\text { Mede o valor total de bens e serviços } \\
\text { Para o uso final produzido antes da dedução do } \\
\text { consumo de capital fixo dividido pelo número de } \\
\text { habitantes de cada município. }\end{array}$ & $\begin{array}{l}\text { Em reais } \\
(\mathrm{R} \$)\end{array}$ & IBGE $^{3}$ \\
\hline
\end{tabular}

Notas:

1 Ministério da Previdência Social (2015). Estatísticas Municipais 2000 a 2014. Disponível em: http://www.previdencia.gov.br/dados-abertos/dados-abertos-previdencia-social/;

2 Fundação João Pinheiro Minas Gerais (2015). Índice mineiro de responsabilidade social. Disponível em: http://imrs.fjp.mg.gov.br/Consultas;

${ }^{3}$ Instituto Brasileiro de Geografia e Estatística (2012). Síntese dos Indicadores Sociais: uma análise das condições de vida da população brasileira. ftp://ftp.ibge.gov.br/Indicadores_Sociais/Sintese_de_Indicadores_Sociais_2012/SIS_2012.pdf

Fonte: Elaborado pelos autores.

O período analisado é o ano de 2010, em virtude de ser a base de dados mais recente relacionada às variáveis disponibilizadas pelas fontes de dados mencionadas anteriormente. Dessa forma, todas as variáveis da Tabela 1 foram coletadas considerando a divulgação anual dos dados, para o ano de 2010.

O universo de análise compreende os 853 municípios do estado de Minas Gerais. Porém, a variável dependente, Arrecadação Previdenciária per capita, contém 320 observações a menos que as demais, pois são dados faltosos na base de dados do Ministério da Previdência Social, assim, a pesquisa foi realizada com dados de 533 municípios de Minas Gerais.

Revista Brasileira de Políticas Públicas e Internacionais, v.2, n.2, Dezembro/2017, pp. 135-151. 
GOUVEIA, Aline G. P.; HORSTH, Tarrara A.; FARONI, Walmer. Análise quantílica dos fatores de influência na arrecadação do Regime Geral de Previdência Social em Minas Gerais

Minas Gerais foi escolhido por representar o estado com o maior número de municípios no país (15,3\%) e por retratar expressivas disparidades regionais provenientes da coexistência de regiões modernas e atrasadas, além de ser o segundo maior em número de habitantes dentre as Unidades da Federação (IBGE, 2011).

Ademais, no que se refere à Previdência Social, a população de Minas Gerais apresentouse em 2010, como a segunda maior beneficiária dos recursos emitidos, correspondendo a 11,27\% dos benefícios pagos a nível nacional. No mesmo período, arrecadação previdenciária do estado foi responsável por 8,89\% do total do país, sendo a terceira posição em arrecadação para o RGPS, ficando atrás apenas de São Paulo e Rio de Janeiro (MPS, 2010).

\subsection{Tratamento dos dados}

Para conhecer como as variáveis socioeconômicas, apontadas pela literatura, influenciam os diferentes níveis de arrecadação previdenciária do RGPS nos municípios de Minas Gerais no ano de 2010 procedeu-se a estimação de uma Regressão Quantílica (RQ). O modelo foi proposto por considerar diferentes grupos de distribuição da variável dependente, a Arrecadação Previdenciária per capita. Assim, é possível conhecer como os mesmos fatores se comportam de acordo com diferentes níveis de arrecadação previdenciária.

A base teórica do método, de que o efeito das variáveis independentes sob a variável dependente se altera ao longo dos quantis, foi desenvolvida e comprovada nos estudos de Koenker e Bassett (1978) e Koenker e Hallock (2001). O método é indicado para aplicações cuja necessidade é a realização de inferências mais precisas e robustas para cada intervalo da distribuição da variável dependente (Pinto, Coronel, Vieira, \& Ceretta, 2015; Santos, 2012). Esse intervalo é conhecido como quantil, e engloba a frequência acumulada da distribuição, assim, no quantil mediano (0.5) estão todos os municípios cuja soma da Arrecadação per capita é a metade do valor total.

Além da vantagem na análise por quantil, em relação à Regressão Linear Múltipla (RLM), a Regressão Quantílica também é um método robusto aos outliers existentes na variável a ser explicada, pois seu estimador, o método de Minimização dos Erros Absolutos (MEA) é baseado na mediana e não na média dos valores observados (Cameron e Triverdi, 2009). Os pressupostos da RLM, como a homocedasticidade dos resíduos, lineariedade dos coeficientes, ausência de auto

Revista Brasileira de Políticas Públicas e Internacionais, v.2, n.2, Dezembro/2017, pp. 135-151. 
GOUVEIA, Aline G. P.; HORSTH, Tarrara A.; FARONI, Walmer. Análise quantílica dos fatores de influência na arrecadação do Regime Geral de Previdência Social em Minas Gerais

correlação serial nos resíduos, multicolinearidade entre as variáveis independentes e a normalidade dos resíduos não são necessários para estimações com o MEA. Assim, os testes de multicolinearidade - VIF, de heteroscedasticidade - Breusch-Pagan, de presença de outliers pela distância de Leverage e de normalidade dos resíduos - Shapiro-Francia -, são indicados para opção entre a RLM ou a RQ (Greene, 2003).

Para validação do método de RQ, o teste de Wald deverá ser aplicado em cada uma das variáveis explicativas, para comprovar a diferença interquantil existente (Greene, 2003). O software escolhido para calcular o coeficiente e os demais procedimentos estatísticos foi o STATA (Data Analysis and Statistical Software).

\section{Resultados e discussões}

Inicialmente foram analisadas as estatísticas descritivas (Tabela 2) das variáveis de estudo, para melhor conhecer o conjunto de dados utilizado.

Tabela 2: Estatísticas Descritivas

\begin{tabular}{|c|c|c|c|c|c|c|}
\hline Variável & $\mathbf{N}$ & Média & Mediana & $\begin{array}{r}\text { Desvio } \\
\text { Padrão }\end{array}$ & Mínimo & Máximo \\
\hline $\begin{array}{l}\text { Arrecadação } \\
\text { Previdência p.c. }\end{array}$ & 533 & 347.306 & 128.45 & 343.009 & 1.690 & 4483.470 \\
\hline $\begin{array}{l}\text { Taxa de } \\
\text { fecundidade }\end{array}$ & 853 & 2.037 & 2.010 & 0.355 & 1.330 & 3.220 \\
\hline $\begin{array}{l}\text { Razão de Dep. } \\
\text { Dem. Idosos }\end{array}$ & 853 & 20.196 & 20.190 & 0.042 & 6.350 & 34.260 \\
\hline Rendimento & 853 & 766.394 & 736.570 & 262.603 & 242.470 & 2437.340 \\
\hline $\begin{array}{l}\text { Taxa de } \\
\text { desemprego }\end{array}$ & 853 & 5.808 & 5.340 & 2.931 & 0.590 & 20.770 \\
\hline $\begin{array}{l}\text { Trabalho } \\
\text { informal }\end{array}$ & 853 & 50.056 & 50.350 & 11.319 & 18.580 & 79.980 \\
\hline PIB p.c. & 853 & 12213.800 & 8511.9500 & 14094.500 & 3593.190 & 239773.600 \\
\hline
\end{tabular}

Nota: O software STATA identifica as variáveis explicativas que não contenham dados para a variável dependente, e as excluí para gerar as estimativas dos modelos de regressões. Porém, para análises descritivas os dados, o software considera os dados das 853 variáveis explicativas, para tornar a informação descritiva do conjunto de dados mais fidedigna à realidade do estado de Minas Gerais.

Fonte: Resultados da pesquisa.

Revista Brasileira de Políticas Públicas e Internacionais, v.2, n.2, Dezembro/2017, pp. 135-151. 
GOUVEIA, Aline G. P.; HORSTH, Tarrara A.; FARONI, Walmer. Análise quantílica dos fatores de influência na arrecadação do Regime Geral de Previdência Social em Minas Gerais

A primeira observação é a grande amplitude da variável dependente, Arrecadação Previdenciária, que indica a presença de outliers, bem como na variável Rendimentos e no PIB per capita. As diferenças entre as médias dos dados e seus respectivos desvios padrão e medianas, indicam uma distribuição altamente dispersa e a presença de outliers.

Para escolher o método de regressão, foram realizados alguns testes: a) de multicolinearidade - VIF -, cujo resultado indicou ausência de multicolinearidade entre as variáveis independentes ( $\mathrm{VIF}=1.40)$; b) de heteroscedasticidade - Breusch-Pagan -, ao qual apontou a presença de erros heterocadásticos (chi2=98.95; prob>chi1 =0.000), indicando que a regressão deve ser estimada com robustez; c) de confirmação de outliers, por meio da realização do cálculo da distância de Leverage (lev>02251407), em que 100 municípios foram considerados outliers nas variáveis; e d) o teste de normalidade dos resíduos - Shapiro-Francia - (W’=0.61083; V'=148.643; Z’=11.017; Prob>z=0.00001), confirmando a não normalidade nos resíduos, indicando que a RQ é mais adequada para o tratamento dos dados que a RLM.

Dessa forma, a Regressão Quantílica foi estimada considerando os quantis: 0.25; 0.50 e 0.75 de distribuição dos valores per capita de Arrecadação Previdenciária. O teste de Wald (0.013 a 0.025) para diferenças interquantis das variáveis independentes apresentou considerável diferença entre os coeficientes estimados para cada quantil, validando o método de estimação da RQ.

Os limites de cada quantil estão expostos na Tabela 3:

Tabela 3: Distribuição dos limites dos quantis

\begin{tabular}{ccc}
\hline Quantil & Limite Inferior & Limite Superior \\
\hline 0.25 & 1.69 & 271.02 \\
\hline 0.50 & 271.04 & 459.55 \\
\hline 0.75 & 461.26 & 4483.47
\end{tabular}

Fonte: Resultados da pesquisa

O modelo de regressão estimado em conformidade com os pressupostos e assim, reconhecendo sua validação, permite a comparação dos resultados obtidos da análise multivariada com o que preconiza a literatura, conforme a Revisão Bibliográfica apresentada. A comparação

Revista Brasileira de Políticas Públicas e Internacionais, v.2, n.2, Dezembro/2017, pp. 135-151. 
GOUVEIA, Aline G. P.; HORSTH, Tarrara A.; FARONI, Walmer. Análise quantílica dos fatores de influência na arrecadação do Regime Geral de Previdência Social em Minas Gerais

pode ser observada na Tabela 4, que apresenta os coeficientes estimados pela Regressão Quantílica, com seus devidos erros padrão e níveis de significância, bem como uma coluna de relação com a literatura-base dessa pesquisa.

Tabela 4: Comparação da literatura com os resultados obtidos

\begin{tabular}{|c|c|c|c|c|c|c|c|}
\hline \multirow[b]{2}{*}{ Variáveis/ Quantis } & \multirow[b]{2}{*}{ Literatura } & \multicolumn{6}{|c|}{ Coeficientes } \\
\hline & & q.025 & & q.0.50 & & q.0.75 & \\
\hline \multirow[t]{2}{*}{ Taxa de fecundidade } & $(+)$ & -69.700 & $* * *$ & -86.077 & $* * *$ & -104.522 & $* * *$ \\
\hline & & (23.796) & & $(32.832)$ & & $(59.545)$ & \\
\hline \multirow[t]{2}{*}{ Razão de Dep. da Idade } & $(-)$ & -131.785 & & -31.832 & & 321.147 & \\
\hline & & $(236.100)$ & & $(286.885)$ & & $(384.700)$ & \\
\hline \multirow[t]{2}{*}{ Rendimento } & $(+)$ & 0.385 & $* * *$ & 0.431 & $* * *$ & 0.546 & $* * *$ \\
\hline & & $(0.046)$ & & $(0.053)$ & & $(0.067)$ & \\
\hline \multirow[t]{2}{*}{ Taxa de desemprego } & $(-)$ & 1.383 & & 5.783 & $*$ & 9.465 & \\
\hline & & $(3.077)$ & & (3.493) & & $(5.941)$ & \\
\hline \multirow[t]{2}{*}{ Trabalho informal } & $(-)$ & -0.985 & & -2.990 & $* * *$ & -3.866 & $* *$ \\
\hline & & $(0.749)$ & & $(0.885)$ & & $(1.701)$ & \\
\hline \multirow[t]{2}{*}{ PIB per capita } & $(+)$ & 0.000 & & 0.002 & $* *$ & 0.002 & $* *$ \\
\hline & & $(0.002)$ & & $(0.001)$ & & $(0.001)$ & \\
\hline \multirow[t]{2}{*}{ Constante } & & 78.041 & & 207.489 & $*$ & 225.847 & \\
\hline & & (74.184) & & $(117.410)$ & & (177.243) & \\
\hline
\end{tabular}

Algumas das variáveis obtidas através da regressão quantílica são condizentes com a expectativa literária, outras divergentes. Assim, se faz necessário discutir os resultados encontrados para as variáveis de acordo com os quantis de arrecadação.

A variável de Razão de Dependência Demográfica dos Idosos, embora defendida pela literatura como uma variável de impacto negativo, não se mostrou significativa em nenhum dos Revista Brasileira de Políticas Públicas e Internacionais, v.2, n.2, Dezembro/2017, pp. 135-151. 
GOUVEIA, Aline G. P.; HORSTH, Tarrara A.; FARONI, Walmer. Análise quantílica dos fatores de influência na arrecadação do Regime Geral de Previdência Social em Minas Gerais

quantis para os municípios mineiros em 2010. Os autores Santos (2004) e Leite et al. (2010) argumentam que quanto maior o número de idosos em relação à população ativa menor a parcela de contribuintes, porém é possível inferir que essa premissa não se aplica à arrecadação do ano em estudo para os municípios do caso. Além disso, é uma variável que tende a impactar mais significativamente os benefícios emitidos, ou seja, as despesas previdenciárias, visto que quanto maior o número de idosos maior a demanda por benefícios.

A taxa de desemprego em municípios nos quantis baixo e alto não foi significativa, ao contrário daqueles com arrecadação média (quantil 0.50). Apesar de baixa significância, conforme exposto na Tabela 4, a TDES apresentou-se inversa à expectativa literária (Leite et al., 2010) que a apontou prejudicial à arrecadação previdenciária. O comportamento desta variável pode estar relacionado às baixas taxas de desemprego dos municípios mineiros para o ano de estudo. Apenas 8,8\% dos municípios possuíam taxa de desemprego superior a 10\%, em 2010.

A taxa de fecundidade se apresenta como significativa em todos os quantis de APC, entretanto, seu coeficiente negativo contraria os resultados apontados por Santos (2004), pois quanto maior o quantil, maior a interferência negativa do aumento da taxa de fecundidade. Em municípios com arrecadação per capita acima de R \$ 461,26, para cada 1\% de aumento na taxa de fecundidade, há o decréscimo de quase R\$ 105,00 na arrecadação per capita.

O trabalho informal também impacta negativamente a arrecadação do RGPS, principalmente nos quantis mediano e alto. Conforme exposto por Silva et al. (2014), a arrecadação previdenciária tem como principal fonte a folha de pagamento das empresas e a contribuição dos trabalhadores. Ao passo que os indivíduos prestam trabalho informal sem recolherem como autônomos, a arrecadação é prejudicada.

O modelo de regressão confirma a influência positiva do fator rendimento. Conforme exposto por Klieber (2004) e Leite et al. (2010), este afeta o resultado financeiro, visto que o aumento na renda proporciona crescimento na arrecadação; assim como a possibilidade de aumento dos futuros beneficiários.

Em relação ao PIB, Silva (2014) o relaciona com o resultado positivo para a arrecadação, visto que o crescimento econômico propicia a geração de novos empregos e assim, o aumento das contribuições; confirmado pelos resultados desta pesquisa.

Revista Brasileira de Políticas Públicas e Internacionais, v.2, n.2, Dezembro/2017, pp. 135-151. 
GOUVEIA, Aline G. P.; HORSTH, Tarrara A.; FARONI, Walmer. Análise quantílica dos fatores de influência na arrecadação do Regime Geral de Previdência Social em Minas Gerais

De modo geral, com exceção da taxa de desemprego, as variáveis analisadas para o estado de Minas Gerais, respeitando suas proporções, apresentam comportamento similar quando comparadas aos estudos a nível nacional, referenciadas neste estudo, como os realizados por Santos (2004), Leite et al. (2010), Silva et al. (2014) e Lima (2013). Porém neste estudo, é possível perceber que as influências das variáveis aumentam de acordo com o aumento da arrecadação, pois, elas tiveram níveis de significância maiores e coeficientes mais elevados no quantil 0.75, que no quantil 0.25, que apresentou apenas a Taxa de Fecundidade e o Rendimento como variáveis significantes.

Empiricamente, a diferença percebida do comportamento das variáveis explicativas entre os diferentes níveis de arrecadação é a contribuição mais relevante para análise da Regressão Quantílica em detrimento da Regressão Linear Múltipla, normalmente utilizada nos estudos relacionados a este tema.

\section{Considerações finais}

Perante o objetivo do estudo de identificar os fatores que influenciam os diferentes níveis de arrecadação previdenciária do RGPS no contexto dos municípios mineiros, constatou-se que o rendimento, assim como o PIB exercem influência positiva na arrecadação desses municípios, enquanto o trabalho informal a decrescem, em consonância com a literatura acerca do tema.

A variável idade representada pela razão de dependência demográfica dos idosos não apresentou significância para o ano e o período de análise em nenhum dos níveis de arrecadação, considerando o grupo de municípios estudados. Enquanto a taxa de desemprego apresentou significância apenas no nível médio de arrecadação, embora contrária ao exposto pela literatura acerca do tema. Neste sentido, podem ser realizados estudos mais aprofundados que envolvam o contexto em municípios de outros estados ou a nível nacional para comparação dos resultados.

De modo geral, é possível perceber que as influências das variáveis aumentam de acordo com o aumento da arrecadação, reafirmando a importância e adequação do modelo de análise proposto para este estudo (RQ) e os benefícios de sua utilização em pesquisas que envolvem unidades de análise com proporções distintas como os municípios mineiros; e por apresentar

Revista Brasileira de Políticas Públicas e Internacionais, v.2, n.2, Dezembro/2017, pp. 135-151. 
GOUVEIA, Aline G. P.; HORSTH, Tarrara A.; FARONI, Walmer. Análise quantílica dos fatores de influência na arrecadação do Regime Geral de Previdência Social em Minas Gerais

resultados mais próximos à realidade financeira das receitas previdenciárias em que cada município se encontra.

Assim, a arrecadação está relacionada aos aspectos socioeconômicos, financeiros e demográficos, representados neste trabalho pela taxa de fecundidade, rendimento, taxa de desemprego, taxa de mortalidade, trabalho informal e pelo PIB per capita. Estes fatores influenciam a arrecadação e interferem na garantia de pagamento dos benefícios previdenciários à população dos municípios mineiros no ano de 2010. Estes benefícios são responsáveis pela distribuição de renda entre a população, assim como pela melhoria da qualidade de vida, garantia de proteção social e fortalecimento da economia dos pequenos municípios, entre outros aspectos que ratificam a Previdência Social como umas das principais políticas públicas do país.

Com base neste estudo, sugere-se novas pesquisas em prol da formulação de políticas que visem resguardar o sistema previdenciário perante mudanças no cenário econômico e social, visto que a arrecadação a nível municipal do RGPS pode ser comprometida por fatores como o aumento do trabalho informal, a diminuição do PIB ou da renda, entre outros. A fim de propiciar o equilíbrio financeiro e atuarial e consequentemente a sustentabilidade do sistema a médio e longo prazo.

\section{Referências}

Afonso, L. E. (2003). Um Estudo dos Aspectos Distributivos da Previdência Social no Brasil. Tese de doutorado, Universidade de São Paulo, São Paulo, Brasil.

Além, A. C. D., \& Giambiagi, F. (1997). Despesa previdenciária: análise de sua composição, efeitos da inflação e bases para uma alternativa intermediária de reforma. Planejamento e Políticas Públicas, (16).

Bertussi, L. A. S., \& Tejada, C. A. (2003). Conceito, estrutura e evolução da previdência social no Brasil. Teoria e Evidência Econômica, 11(20), 27-55.

Cavalieri, C., \& Pazello, E. (2005). Efeito distributivo das políticas sociais. Economia do setor público no Brasil. Rio de Janeiro: Campus.

Caetano, M. A. (2006). Determinantes da Sustentabilidade e do Custo Previdenciário: Aspectos Conceituais e Comparações Internacionais. Brasília: IPEA.

Cameron, A. C., \& Trivedi, P. K. (2009). Microeconometrics Using Stata. Texas: Stata Press.

Revista Brasileira de Políticas Públicas e Internacionais, v.2, n.2, Dezembro/2017, pp. 135-151. 
GOUVEIA, Aline G. P.; HORSTH, Tarrara A.; FARONI, Walmer. Análise quantílica dos fatores de influência na arrecadação do Regime Geral de Previdência Social em Minas Gerais

Carvalho, I. E. F. (2012). Household income as a determinant of child labor and school enrollment in Brazil: Evidence from a social security reform. Economic Development and Cultural Change, 60(2), 399-435.

Cordeiro, G. F. (2006). O regime geral de previdência social: diagnósticos estruturais críticos e proposta de reformas. Dissertação de mestrado, Escola Brasileira de Administração Pública, Rio de Janeiro, Brasil.

Ferraro, S. A. (2010). O equilíbrio financeiro e atuarial nos regimes de previdência social. Rio de Janeiro: Lumen Juris.

França, A. S. (2004). Previdência social e a economia dos municípios. Brasília: Associação Nacional dos Auditores Fiscais da Receita Federal do Brasil.

Greene, W. H. (2002). Econometric Analysis. (5a ed). New Jersey: Prentice Hall.

Hoffmann, R. (2010). Como aposentadorias e pensões afetam a educação e o trabalho de jovens do domicílio. Revista Economia e Sociedade, 19(38), 201-209.

Instituto Brasileiro de Geografia e Estatística (2011). Minas Gerais. Disponível em: http://www.ibge.gov.br/estadosat/perfil.php?sigla=mg

Instituto Brasileiro de Geografia e Estatística (2012). Síntese dos Indicadores Sociais: uma análise das condições de vida da população brasileira. Disponível em: ftp://ftp.ibge.gov.br/Indicadores_Sociais/Sintese_de_Indicadores_Sociais_2012/SIS_2012.pdf

Instituto Nacional do Seguro Social (2009). Previdência Social: Reflexões e Desafios. Disponível em: http://www.inss.gov.br/arquivos/office/3_100202-164641-248.pdf .

James, E. (2001). Novos sistemas previdenciários: experiências, evidências e questões pendentes. Brasília: MPAS/SPS.

Ellery, R. G., \& BUGARIN, M. N. S. (2003). Previdência social e bem-estar no Brasil. Revista Brasileira de Economia, 57(1), 27-57.

Klieber, E. J., Buffin, K. G., \& Burrows, E.E. (2004). Assumptions used to project Social Security’s financial condition. Washington, DC: American Academy of Actuaries.

Koenker, R., \& Bassett, G. (1978). Regression Quantiles. Econometrica: Journal of the Econometric Society, 46, 33-50,

Koenker, R., \& Hallock, K. F. (2001). Quantile Regression. Journal of Economic Perspectives, 15(4), 143-156.

Leite, A. R., Ness, W. L., \& Klotzle, M. C. (2010). Previdência Social: fatores que explicam os resultados financeiros. Revista de Administração Pública-RAP, 44(2), 437-57.

Lima, D. V. (2013). A dinâmica demográfica e a sustentabilidade do modelo de financiamento do regime geral de previdência social. Tese de Doutorado, Universidade de Brasília, Universidade Federal da Paraíba, Universidade Federal do Rio Grande do Norte, Brasília, Brasil.

Revista Brasileira de Políticas Públicas e Internacionais, v.2, n.2, Dezembro/2017, pp. 135-151. 
GOUVEIA, Aline G. P.; HORSTH, Tarrara A.; FARONI, Walmer. Análise quantílica dos fatores de influência na arrecadação do Regime Geral de Previdência Social em Minas Gerais

Miranda, A. L. F. et al. (2010). O Déficit da Previdência Social: análise comparativa entre as duas linhas metodológicas divergentes. Monografia, Universidade Federal de Santa Catarina - UFSC, Curitiba, Santa Catarina, Brasil.

Ministério da Previdência Social. (2010). Boletim Estatístico da Previdência Social. Disponível em: www.mpas.gov.br/conteudoDinamico.php?id=482 .

Oliveira, F. E. B. (1992). Proposta de um referencial básico para a discussão da seguridade social. Rio de Janeiro: IPEA.

Pinto, N. M., Coronel, D. A., Vieira, K. M., \& Ceretta, P. S. (2015). A influência dos fatores socioeconômicos no endividamento dos municípios do Rio Grande do Sul. Revista Brasileira de Gestão e Desenvolvimento Regional, (11)1, 393-419.

Ramos, L. (2007). O desempenho recente do mercado de trabalho brasileiro: tendências, fatos estilizados e padrões espaciais. Rio de Janeiro: IPEA.

Reis, P. R. C., Silveira, S. F. R., \& Braga, M. J. (2013). Previdência social e desenvolvimento socioeconômico: impactos nos municípios de pequeno porte de Minas Gerais. Revista Brasileira de Administração Pública - RAP, 47(3).

Santos, B. R. (2012). Modelos de Regressão Quantílica. Dissertação de Mestrado, Universidade de São Paulo, São Paulo, Brasil.

Santos, N. M. G. (2004). Um estudo prospectivo sobre a Previdência Social brasileira. Tese de Doutorado, Universidade Federal do Rio de Janeiro, Rio de Janeiro, Brasil.

Silva, L. L., Costa, T. M. T., \& Dias, W. B. (2014). Impacto de Variáveis Macroeconômicas nas Receitas e Despesas do Regime Geral da Previdência Social no Brasil. In: VI Encontro de Administração Pública e Governança, 2014, Belo Horizonte, Minas Gerais, Brasil.

Silva, L. L. (2014). Formação do Sistema Previdenciário Brasileiro: fatores históricos $e$ econômicos. Dissertação de Mestrado, Universidade Federal de Viçosa, Viçosa, Minas Gerais, Brasil.

Silveira, F. G. (2008). Tributação, previdência e assistência sociais: impactos distributivos. Tese de Doutorado, Universidade Estadual de Campinas, Instituto de Economia, Campinas, São Paulo, Brasil.

Thompson, L. (2000). Mais velha e mais sábia: a economia dos sistemas previdenciários. Brasília: MPAS/SPS.

Revista Brasileira de Políticas Públicas e Internacionais, v.2, n.2, Dezembro/2017, pp. 135-151. 